\title{
El arbitraje y la conciliación: una mirada en los arbitrajes nacionales e internacionales con sede en Chile
}

\author{
Ricardo Riesco Eyzaguirre*
}

\begin{abstract}
SUMARIO
1. Algunas particularidades sobre el arbitraje en Chile. 2. La conciliación como forma frecuente de terminación de los arbitrajes nacionales. 3. La conciliación en la LACI. 4. Procedencia de la conciliación en los arbitrajes comerciales internacionales con sede en Chile. 5. Conclusiones.
\end{abstract}

\section{Algunas particularidades sobre el arbitraje en CHILE}

En el año 2004, Chile pasó a engrosar el listado de países que cuentan con un sistema dualista de arbitraje comercial.

Por una parte, el arbitraje comercial doméstico o arbitraje nacional -que, en términos generales, tiene lugar cuando se resuelve una disputa entre chilenos emanada de un contrato celebrado y para ser ejecutado en Chile, sin que exista ningún factor de conexión con el extranjero-se encuentra regulado en el Código Orgánico de Tribunales del año $1943(\underline{\mathrm{COT}})^{1}$ y en el

- Profesor de Derecho Procesal de la Pontificia Universidad Católica de Chile. Árbitro del Centro de Arbitraje y Mediación de la Cámara de Comercio de Santiago A.G. LL.M. Universidad de Columbia, Nueva York. Abogado asociado senior en el estudio juridico chileno Philippi Yrarrázaval Pulido \& Brünner Abogados: 
El Arbitraje y la Conciliación: una mirada en los arbitrajes

nacionales e internacionales con sede en Chile

Código de Procedimiento Civil del año 1903 (CPC) $)^{2}$. El arbitraje comercial doméstico en Chile tiene una larga tradición y goza de un enorme reconocimiento como mecanismo de resolución de disputas, particularmente cuando se trata de conflictos contractuales de gran relevancia ${ }^{3}$. Prueba fehaciente de ello, entre otras cosas, es que el artículo 227 del COT consagra incluso ciertos casos de arbitraje forzoso ${ }^{4}$, contrariando así el principio general que propugna la voluntariedad primigenia del arbitraje. Sin perjuicio de que la regulación normativa aplicable al arbitraje nacional es muy antigua y en parte fue dictada hace ya más de un siglo, nuestra jurisprudencia -que en términos generales siempre ha apoyado y respetado el arbitraje en Chile- se ha encargado paulatinamente de incorporar los principios modernos e internacionalmente reconocidos en materia de arbitraje, tales como el principio de la autonomía de la cláusula arbitral ${ }^{5} \mathrm{y}$

1. COT. Titulo IX, artículos 222 a 243 . El primer reconocimiento y regulación sistemática del arbitraje en Chile se remonta a la Ley Orginica de Tribunales de 1875. Para mayores detalles, vid. EYZAGUIRRE ECHEVERRIA. Rafacl, El Arhitraje Concreial en la Legislaciön Chilena y su Regulacióm Internacional, Editorial Juridica de Clite, 1981, p. 19.

2. CPC, Libro III. Titulo VIII, articulos 628 a 644 .

3. En coincidencia con esta opinión, vid. MEREMINSKAYA, Elina, "Arbitraje Doméstico v Intemacional en Chile: En Búsqueda de la Armonia", cn Revista de Arbitraje y Mediacién en Las Amiricus, p. 97; y FERNÄNDEZ RUIZ, Gonzalo, "Arbitraje Comercial Intemacional en Chile: Marco Legal y Jurisprudencia", en El Arbitraje Comercial Internacional en Latinoamérica, Marco Legal y Jurispnudencial, Cuatrecasas, Gonçalves Percira, Legis, 2009, p. 289.

4. El anticulo 227 del COT establece: "Dehen resolverse por arbitms los asuntes siguientes:

1. La liquidación de una sacicdad connugal o de una sociedal colectiva o en comandita ciril. y la de las commudades; 2. La particion de bienes; 3 . Las cuestiones a que diere lingar la prescutaciein de la cuenta del gerente o del liquidador de las socicdades comerciales y los demás juicios sobre cuentas. 4. Las diferencias que octurricren cntre los socios de una socictad aninima, o de una socicdad colectiva a en comandita comercial. o entre los asociados de una participacion. en el caso del articulo +15 del Código de Comercio; 5. Los demas que determinen las leyes. Pueden, sin embarge, los interesados resolver por si mismos estos negocios, si todos ellos ticnen la libre dispasicion de sus hienes y concurren al acto. sin perjuicio de lo dispuesto en el articulo $6+5$ dcl Código de Procedimiento Civir". Por otro lado y en lo que respecta a los requisitos que deben contener los estatutos de una sociedad anónima en Chile, el articulo $4, N^{2} 10$ de la Ley $N^{\circ} 18046$, sobre Socicdades Anónimas, scinala que "La escritura de la sociedad debe expresar: (...) 10, La naturaleza del arhitraje a que deherain ser sometidas las difenencias que ocurran entre los accionistas en su calidad de tales, o centre estes y la sociedad o sus administradores, sea dirante la vigencia de la socicdad o durante su liguidacioin. Si nada se dijere, se entendera que las diferencias serin sometidas a la resolucioin de un arbitro arbitruder".

5. Vid. sentencia recaida en el proceso caratulado "Calaados La Florida Limiada con Calzades Crillón Limitada". Corte de Apelaciones de Santiago, 28 de mayo de 1980; y sentencia recaida en el proceso caratulado "Carter Holt Harvey con inversiones Secomma", Corte de Apelaciones de Santiago, 25 de julio de 1995. Nuestra doctrina, por su parte, también reconoce el principio de la autonomia de la cláusula arbitral. Vid.. AYLWIN AZÓCAR, Patricio, El Juicio drbitral, Quinta Ediciön, Editorial Juridica de Chile, 2005, p. 303: "La cläusula compromisoria es un contrato con fisonomia juridica 
el principio de Kompetenz-Kompetenz, aunque en este último caso siempre que no se impugne la validez de la propia cláusula arbitral de la cual se deriva la jurisdicción y competencia del árbitró.

Por otra parte, el arbitraje comercial internacional -que, en términos generales, tiene lugar cuando se resuelve una disputa que involucra al menos a una parte extranjera o tiene cualquier otro factor de conexión real y razonable con el extranjero- se encuentra regulado por la Ley $\mathrm{N}^{\circ} 19.971$, de 29 de septiembre de 2004 (LACI), que constituye una réplica exacta de la Ley Modelo sobre Arbitraje Comercial Internacional de la CNUDMI de 19857. El propósito principal perseguido por Chile al dictar la LACI, además de llenar un evidente vacío normativo impropio de un país completamente abierto al comercio internacional", era transformar a Santiago de Chile en una sede relevante de arbitrajes comerciales internacionales. En el Mensaje de la Ley enviado por el

propia e independiente (...J". A cste respecto, el inciso $2^{\circ} \mathrm{del}$ articulo 23 del Reglamento Procesal de Arbitraje Doméstico del Centro de Arbitraje y Mediación de la Cámara de Comercio de Santiago A.G. scnala que "El tribunal arbisral estará faculiado para deterninar la existencia o la validez del comrato del que forma parte una clausula compronnisuria. Para cstos efectos, una clatasula campromisoria que forme parte de un contrato y que disponga la celebracion del arbitraje con arreglo al presente Reglameno. se considerará como un acuento independiente de lass demais estipulaciones ded contrato. La decisión del tribunal arbitral de que cl contrafo es molo no entrañará ipso jure la invalidez de la cláusula compromisoria ni viceversa".

6. Vid. sentencia recaida en el proceso caratulado "Sociedad Elizaheth dalau y Compañia Limitada", Corte Suprema, 6 de octubre de 1993; sentencia recaida en el proceso caratulado "Chilectra Afesmopolitant". Conte Suprema, 5 de abril de 1994; y sentencia recaida en el proceso caratulado "Patricio Mfillas Ovalle con Juez del 250 Juzgado Civil de Santiago", Conte Suprema, 26 de marzo de 1996. Para un análisis critico de cstas scntencias, vid. VÁSQUEZ PALMA, MARIA FERNAN. DA, Arbitruje en Chile, Análisis Critico de su Normativa y Jurisprzalencia, LegalPublishing, 2009. p. 216. A este respecto, el inciso $!^{\circ}$ del articulo $23 \mathrm{del} \mathrm{Regjancnto} \mathrm{Procesal} \mathrm{de} \mathrm{Arbitraje} \mathrm{Doméstico}$ del Centro de Arbitraje y Mediación de la Cámara de Comercio de Santiago A G, señala que "El tribumal arbitral podra decidir respecto de la exis/cucia o valide de la cläusula compromisorias y de la excepción de incompetencia del trihunal, la que deberá ser opuesta en el escrito de contestación a la demanda, o con respecro a ma reconchción, en la contesacion a esa recomencion. El tribunal arbitral decidiri como cutestion previa las excepciones relativas a su competencia".

7. A partir del año 1975 y 1976, respectivamente, Chile es signatario de la Convención de Nueva York y de la Convención de Panamá.

8. A csta fecha, Chile ha suscrito nada menos que 19 acuerdos comercialts internacionales -entre Acuerdos Reciprocos de Protección de Inversiones, Acuerdos de Asociación Económica y Tralados de Libre Comercio que involucran a 55 paises del mundo, encontrándose otros en proceso de negociaciones. Para mayores detilles al respecto, vid. el cuadro resumen de acterdos comerciales internacionales contenido en la página web de la Dirección General de Relaciones Económicas Intemacionales del Ministerio de del Gobietno de Chile (www dirccon.cl), o bien IRARRAZABAL. Jaime y RIESCO, Ricardo, "Arhitration in Chile", en dibbiration in 47 Jurisdictions Wortduite, Glohal Arhitration Review \& Getting the Deal Through, 2009. 
El Arbitraje y la Concilinción: una mirada en los arbitrajes

nacionaies e internacionales con sede on Chile

Presidente de la República de la época, don Ricardo Lagos Escobar, se indicaba textualmente que "El prestigio de Chile en términos de institucionalidad, solvencia juridica y altos índices de transparencia hacen de Chile un centro natural de arbitraje en América Latina" ${ }^{\prime \prime}$.

Si bien este objetivo aún no se ha conseguido a cabalidad -cabe señalar, eso sí, que otros países también pretenden que una o más de sus ciudades se constituyan en sedes relevantes para la resolución de arbitrajes comerciales internacionales que involucren a partes iberoamericanas, tales como Miami, Madrid, Ciudad de México, Lima, etc.-, al menos la jurisprudencia nacional, siguiendo la misma tendencia que en el marco del arbitraje comercial doméstico, ha dado su apoyo al arbitraje comercial internacional en Chile, interpretando y aplicando en forma correcta diversas disposiciones de la LACI. En efecto, los tribunales chilenos han resuelto:

(i) Que la LACI se aplica in actum cuando concurren sus presupuestos de aplicación y que en el marco de arbitrajes internacionales con sede en Chile no proceden sino los limitadísimos recursos que establece la $\mathrm{LACI}^{10}$;

(ii) Que ante la existencia de una cláusula arbitral contenida en un contrato, el tribunal ordinario de justicia no puede sino remitir a las partes a arbitraje ${ }^{i}$;

9. Vid. Mensaje de S.E el Presidente de la Republica con el que Inicia un Proyecto de Ley sobre Arhitraje Comencial Internacional, $\mathrm{N}^{\circ} 15-349$, de 2 de junio de 2003, p. 3. No obstante, también existía una cierta confusión respecto de los poteneiales beneficios que podia traer aparejada la dictación de la LACl, to que queda de manifiesto en que el mismo Mensaje Presidencial señalaba que "Resulsa convenicute a les intercses de las parter nacionales en las transacciones internacionales que ellas cuenten con los mecanismos tegales adccuados para, en la medida de lo posible, estimular que las diferencias comerciales sean resuchas en Chilc. Evidententente, esta necesidad es más apremiante para las empresas pequeñas y medianas a las cuales les resula demasiado onemoso litigar en el extranjero". Es muy improbable que una ley de arbitraje comercial internacional pueda trace aparejado beneficios para las pequeñas y medianas empresas de un pais, toďa vez que ellas ciertamente carecen del poder de negociación para imponer a sus contrapartes extranjeras que la sede en que se resuelvan sus dispuas se ubique en su propio pais, quedando también sujetos, en mayor o menor medida, a los tribunates ordinarios de dicho pais.

10. Vid. sentencia dictada por la Corte de Apelaciones de Santiago con fecha 3 de mayo de 2006 en el proceso Rel N88-2006, y seniencia dictada por la Corte de Apelaciones de Santiago con fecha 25 de mayo de 2006 en el proceso Rol No865-2006.

11. Vid. sentencia dietada por el $21^{\circ}$ Juzgado Civil de Santiago con fecha 2 de noviembre de 2007 en el proceso Rol N${ }^{\circ} 6361-2006$. 
(iii) Que en el proceso de exequátur tendiente al reconocimiento de un laudo arbitral internacional sólo procede analizar las causales específicas contempladas para denegar su reconocimiento, pero no es posible analizar el fondo de la cuestión debatida en el arbitraje ${ }^{12}$;

(iv) Que las causales para anular un laudo arbitral internacional dictado en Chile son sólo aquellas establecidas en la LACI y que ellas deben ser interpretadas restrictivamente ${ }^{13}$; y

(v) Que es posible reconocer y ordenar ejecutar en Chile, en el marco de un exequátur, un laudo arbitral internacional que está en proceso de anulación en la sede del arbitraje ${ }^{14}$.

Hoy en día, en base a la información disponible en la página web de la CNUDMI (www.uncitral.org), existen más de 60 países que han adoptado legislaciones sobre arbitraje comercial internacional que son similares o idénticas a la Ley Modelo de la CNUDMI de 1985 o 2006. En consecuencia, resulta evidente que, para transformarse en una sede relevante de arbitrajes comerciales internacionales, en ningún caso basta haber dictado una legislación sobre arbitraje comercial internacional que sea similar o incluso idéntica a la Ley Modelo CNUDMI de 1986 o 2006, lo que constituye tan sólo un "punto de partida" para el cumplimiento de dicho objetivo.

De alguna forma, Chile debe ser atractivo y lograr que los contratantes internacionales designen a Santiago de Chile como sede para el conocimiento y resolución de sus conflictos en el marco de arbitrajes comerciales internacionales, lo cual debe reportar ventajas comparativas tangibles para las partes. Con el objeto de que Santiago de Chile efectivamente se transforme o al

12. Vid. sentencia dictada por la Corte Suprema con fecha 15 de septiembre de 2008 en el proceso Rol $\mathrm{N}^{\circ} 6615-2007$.

13. Vid. sentencia dictada por la Corte de Apelaciones de Santiago con fecha 4 de agosto de $2009 \mathrm{cn}$ el proceso Rol N9134-2007.

14. Vid. sentencia dictada por la Corte Suprema con fecha 15 de diciembre de 2009 en el proceso Rol N $5228-2008$. 
El Arbitraje y la Conciliación: una mirada en los arbitrajes nacionales e internacionales con sede e'n Chile

menos tenga mayores posibilidades de transformarse en una sede relevante de arbitrajes comerciales internacionales que involucren a partes iberoamericanas, estimamos que no sólo es necesario que la jurisprudencia nacional siga desarrollándose favorablemente, como hasta ahora, sino que también sería necesario realizar ciertas reformas legales de menor entidad a la LACI, las que servirían para despejar cualquier asomo de duda o potencial de conflicto derivado de las disposiciones de la LACI, lo que constituye un primer objetivo más modesto. En nuestra opinión, dichas reformas debieran ser las siguientes:

(i) Clarificar expresamente en el texto de la LACI que en los arbitrajes comerciales internacionales con sede en Chile pueden intervenir como abogados de parte tanto abogados chilenos como abogados extranjeros. Lo anterior es indispensable a raíz de ciertos comentarios localistas y restrictivos emitidos al respecto por un H. Senador y por el Ministro de Justicia de la época durante el período de discusión de la LACI, quienes señalaron que un tribunal arbitral internacional con sede en Chile es un verdadero tribunal de justicia chileno $y$, por tanto, debe hacer cumplir las normas chilenas imperativas sobre comparecencia en juicio, que sólo permiten la intervención en juicio de abogados chilenos; y

(ii) Garantizar la "finalidad" del laudo arbitral internacional dictado en Chile, lo cual se logra eliminando la competencia de la Corte de Apelaciones respectiva para conocer y resolver el recurso de nulidad, como señala el artículo 34 de la LACI, y entregándosela a la Corte Suprema. En efecto, dicha modificación legal permitiría excluir cualquier interpretación legal que sostuviere que, al menos teóricamente, procedería el recurso de queja ante la Corte Suprema en contra de la sentencia que dicte una Corte de Apelaciones en el marco de un recurso de nulidad interpuesto en contra de un laudo arbitral internacional dictado en Chile. Asimismo, dicha reforma legal permitiría radicar en la Corte Suprema, como máximo tribunal del país, la competencia para conocer de los recursos de nulidad deducidos contra laudos arbitrales internacionales dictados en Chile y, además, la competen- 
cia para conocer de los exequátur tendientes al reconocimiento de laudos arbitrales internacionales dictados en el extranjero, creándose así una jurisprudencia constante y uniforme sobre lo que constituye el "orden püblico procesal" en Chile ${ }^{15}$.

No obstante la existencia de un sistema dualista de arbitraje, en la práctica no existen mayores diferencias entre un arbitraje nacional y un arbitraje comercial internacional con sede en Chile.

La diferencia más sustancial está constituida por el alcance de los recursos disponibles contra el laudo arbitral. Mientras que en contra de un laudo arbitral internacional dictado en Chile sólo procede el recurso de nulidad establecido en el artículo 34 de la LACI, que es igual al contemplado en la Ley Modelo sobre Arbitraje Comercial Internacional de la CNUDMI y es conocido por la Corte de Apelaciones respectiva, en términos generales y al menos teóricamente los laudos arbitrales domésticos están sujetos al mismo régimen de recursos -que contempla el recurso de apelación, el recurso de casación en la forma, el recurso de casación en el fondo ${ }^{16} \mathrm{y}$ el recurso de queja- que las sentencias pronunciadas por los tribunales ordinarios de justicia, los que pueden implicar una prolongada revisión tanto de la forma como del fondo de lo discutido y resuelto en el arbitraje comercial doméstico. A pesar de la existencia de esta posibilidad, constituye una práctica habitual en Chile que las partes renuncien a la interposición de recursos en contra del laudo arbitral doméstico, lo que conforme a la jurisprudencia nacional equivale a limitar los recursos disponibles al recurso de casación en la

15. Para mayores detalles a este respecto, vid. LINDSEY, David y RIESCO, Ricardo, "Selecting Chile as Seat of Arbitration: A Real Option?", en International Business Litigation \& Arbitration, Volume One, Practising Law Institute, 2006.

16. El recurso de apelación constituye la manifestación de la doble instancia en Chile, toda vez que tiene por objeto que el tribunat superior enmiende la resolución del inferior, tanlo en lo que respecta a los hechos como al Derecho, y estâ regulado en los articulos 186 à 230 del CPC. El recurso de casación, que puede traer aparejada la nulidad de una resolución, se refiere a defectos formales acaecidos durante la tramitación del p̣roceso o en la propia resolución -en cuyo caso se llama recurso de casación en la forma - o con defectos en la interpretación o aplicación del Derecho por parte del tribunal inferior -en cuyo caso se llama recurso de casación en el fondo. El recurso de casación se encuentra regulado en los articulos 764 á 809 del CPC. 
El Arbitrajc y la Concilinción: una miradn en los arbitrajes nacionales e internaciontales con sede en Chile

forma por incompetencia, al recurso de casación en la forma por ultrapetita y al recurso de queja ${ }^{17}$, el cual procede en caso de faltas o abusos graves cometidos en la dictación de resoluciones de carácter jurisdiccional ${ }^{18} \mathrm{y}$, en consecuencia, "abre una puerta" para la revisión del fondo de las cuestiones discutidas y resueltas en el arbitraje nacional. El acogimiento de un recurso de queja contra un laudo arbitral doméstico, no obstante, es sumamente excepcional. Un dato muy ilustrativo de la insignificante relevancia de los recursos de queja en el marco del arbitraje nacional es que, desde el año 1992 a la fecha, tan sólo se ha acogido un recurso de queja en contra de los laudos arbitrales domésticos dictados en los más de 1000 arbitrajes conducidos bajo las normas procesales del Centro de Arbitraje y Mediación de la Cámara de Comercio de Santiago A.G. (CAM Santiago), la principal institución arbitral existente en Chile.

A su vez, y en lo que constituye una particularidad que no es común en el arbitraje comercial internacional, la gran mayoría de los arbitrajes nacionales son conocidos y resueltos en Chile por un solo árbitro -esto es, no se trata de tribunales arbitrales colegiados- que, por regla general, reviste el carácter de árbitro

17. Vid. sentencia dictada por la Corte Suprema con fecha 11 de mayo de 1981 en el proceso Ro! N5202. 1981; y sentencia dictada por la Corte Suprema con fecha 29 de abril de 1992 en el proceso Rol $\mathrm{N}^{\circ} 18.553-1991$; y sentencia dictada por la Corte de Apelaciones de Santiago con fecha 17 de octubre de 1994 en el proceso caratulado "Cuenotexa S.A. con Arbitro Sr. Lorenzo de la Ma:a Rivadeneira".

18. El articulo 545 del COT establece: "El recurso de qucja ticne por exchusiva finalidad corregir las fattas o abusos graves cometidos en la dictacion de resoluciones de carácter jurisdiccional. Sólo procederá cuando la falta o abuso se cometa en sentencia interlocutoria que ponga fin al juicio o haga imposible su contimuación o definitiva, y que no scan susceptibles de recurso alguno, ortinario o extraordinario, sin perjuicio de la atribucioin de la Corte Suprema para actuar de oficio en ejencicin de sus facultades disciplinarias. Se exceptuan las sentencias definitivas de primera o inica instancia dictadas por árbitms arbitradores, en cuso caso procederá el recurso de queja, además del recurso de casación en la forma. El fallo que acoge el recurso de queja contendra las consideraciones precisas que denuestren la falta o abuso, asi como los crnores u omisiones manifiestos y graves que los constituyan y que existan en la resolución que motisa el recurso, y determinará las medidas condu. centes a remediar tal falta o abuso. En ninguin caso podrá modificar; cnmendar o invalidar resoiu. ciones judiciales respecto de las cuales la ley contempla recursos jurisdiccionales ordinarios o extraordinarios, salvo que se trate de un recurso de queja interpuesto contra scntencia definitiva de primera o única instancia dictada por ärhims arbitradores. En caso que un tribunal stupcrior de justicia, haciendo uso de sus facultueles disciplinarias, invalide una resolucion jurisdiccional, deberá aplicar la o lus medidas disciplinarias que estime pertinentes, En tal caso, la sala dispondrá que se dé cuenta al tribunal pleno de los antecedentes para los efectos de aplicar las medidas disciplinarias que procedan, atendida la naturaleza de las faltas o abusos, la que no podrá ser inferior a amones. racioin prisada". 
arbitrador, esto es, de árbitro de equidad o ex nequo et bono ${ }^{19}$. Según las estadísticas del CAM Santiago, por ejemplo, el $70 \%$ de los arbitrajes nacionales conducidos conforme a sus reglas desde el año 1992 a la fecha han sido conocidos y resueltos por árbitros de equidad20.

\section{LA CONCILIACIÓN COMO FORMA FRECUENTE DE TERMINACIÓN DE LOS ARBITRAJES NACIONALES}

Aunque carecen de imperio, los árbitros son considerados verdaderos jueces en Chile. De hecho, el artículo 222 del COT define a los árbitros como "los jueces nombrados por las partes, o por la autoridad judicial en subsidio, para la resolución de un asunto litigioso" ${ }^{21 .}$

19. En todo caso, un árbitro ex aequo et hou en Chile no tiene plena libertad ni en cuanto a la forma ni en cuanto al fondo. En lo que respecta al procedimiento, la jurisprudencia nacional ha señalado que $\because$ \%... el árbitro arbitrador no está obligado a guardar en sus procedimientos y en su fallo otras reglas que las que las partes hayan expresado en el acto constitutivo del compromiso, y si éstas nada huhieren señaludo, a las que se establecen para este caso en al Código de Procedimiento Civil, exigencias istas que constituyen las garantias minimas establecidas por la ley a favor de todas las partes interesadas en la controversia, por lo que el árbitro arbitrador no puede haher tramitado el juicio y dictado sentencia definitiva con prescindencia de ellas". Vid. sentencia dictada por la Corte Suprema con fecha 14 de septicmbre de 1986 en el proceso caratulado "Mfanl de la Fuente, Eugenio". El articulo $16 \mathrm{del}$ Reglamento Procesal de Arbitraje del CAM Santiago señala que " $[. .$.$] tratúndose de arhi-$ traje de arbitrador, el tribunal arhitral podrí dirigir el arbitraje del modo que considere apropiado. siempre que se trate a las partes con igualdal y que, en cada etapa del procedimiento, se dé a cada una de las partes plena oportunidad de hacer valer sus derechos". En cuanto al fondo, se ha resuelto que "La facultad del árbitro artitrador de fallar en conciencia no lo eximen de la obligación de fimdamentar sus decisiones, ni autoriza a la arbitrariedad judicial, y por ello cabe conchir que incurrio en falta el arbitro que coarti a una de las partes la posihilidad de solicitar las diligencias de pricha gue hagan posihle que la sentencia sea fruto de la conviccion que emane de los antecedentes y pruchas concretas que se agreguch al proceso y no solamente de apreciaciones puramente subjetivas de los arhitradores". Vid. sentencia dictada por la Corte Suprema con fecha 2 de enero de 1989 en el proceso caratulado "Mackenta Shiell, Luis". Asimismo, la jurisprudencia nacional ha precisado que "Los airbitros deben fallar conforme a la equidad, y sicndo éste un concepto objetivo, en su virtud deben los árhitros respetar las normas del Derecho Positivo que tienen carácter de orden pablicn [...J". Vid. sentencia dietada por la Corte Suprema con fecha I6 de septiembre de $1993 \mathrm{en}$ el proceso caratulado "Abdala Morrong, José".

20. Vid. Information On Line del CAAI Santiago $N^{\circ} 07 / 2010$, disponible en www.camsantiago.cl. Otro dato interesante que ap̧orta el CAM Santiago es que, de los arbitrajes nacionales seguidos bajo sus reglas desde el año 1992 hasta la fecha, un $14 \%$ tuvo una duración inferior a 3 meses; un $16 \%$ duró entre 3 y 6 meses; y un 35\% de los arbitrajes tuvo una duración entre 6 meses y un año.

21. "Acordado el compromiso, designado c instalado legalmente el ärbitro que resolverá los asuntos que se han previsto, este adquiere el caricter de juez $[\ldots]$. El que carezca de imperio para hacer cumplir dirctameme en forma compulsiva sus nesoluciones no le resta el referido carácter de juez $[$....". Vid. sentencia recaida en el proceso "Carter Holt Haney con Inversiones Socoroma", Corte de Apelaciones de Santiago, 25 de julio de 1995. 
El Arbitraje y in Conciliación: una mirada cn los arbitrajes uncionales $e$ internacionales con sede en Chile

Como jueces que son, los árbitros están obligados a cumplir, en la conducción de los arbitrajes nacionales, con aquellos trámites que la legislación procesal civil chilena ha catalogado como "esenciales" en todo proceso legal que se ventile en primera instancia22. Según lo establecido en el artículo 795 del CPC, los llamados "trámites esenciales en primera instancia", cuya omisión puede traer aparejada la nulidad del proceso legal o de la sentencia que recaiga en el mismo, son:

"I...]1. El emplazamiento de las partes en la forma prescrita por la ley23; 2. El llamado a las partes a conciliación, en los casos en que corresponda conforme a la ley; 3 . El recibimiento de la causa a prueba cuando proceda con arreglo a la ley; 4 . La práctica de diligencias probatorias cuya omisión podría producir indefensión; 5 . La agregación de los instrumentos presentados oportunamente por las partes, con citación o bajo el apercibimiento legal que corresponda respecto de aquella contra la cual se presentan; 6 . La citación para alguna diligencia de prueba; $y$ 7. La citación para oír sentencia definitiva, salvo que la ley no establezca este trámite".

Para efectos de la ley procesal chilena, la "conciliación" de que da cuenta el segundo de los "trámites esenciales en primera instancia", que se encuentra regulada en los artículos 262 á 268 del CPC, podemos definirla como el acuerdo de las partes, provocado por el árbitro, quien establece las bases para la resolución del conflicto.

22. Vid. sentencia dictada por la Corte de Apelaciones de Santiago, con fecia If de junio de 1997, en el proceso caratulado "Gähez Z., Ricardo con dgricola Santa Carmen Limitada", Rol N05228-2008.

23. Por regla generalisima, la primera notificación en todo proceso legal ventilado en Chile debe hacerse al demandado en forma personal, de conformidad con lo dispuesto en el articulo 40 del CPC. No obstante, la Corte Suprema, en el marco de un exequatur tendiente a que se reconociera en Chile un laudo arbitral internacional dictado en Rotterdam, Holanda, en contra de una empresa chilena, proceso en el cual ésta aseveró que se habia infringido el orden público nacional toda vez que habia sido notificada de la demanda por fax y no en forma personal, como prescribe la ley procesal chilena, resolvió accrtadamente que la forma de las notiticaciones en el marco de un arbitraje comercial internacional se rige por lo acordado por las partes en la clausula arbitral pertinente -explicita o implicitamente, en este último caso al adoptar las reglas de alguna institución arbitral-y que su valiojez se sujeta a las leyes procesales del pais en que se haya dictado el laudo arbitral internacional. Vid, seniencia dictada por la Corte Suprema con fecha 5 de julio de $1999 \mathrm{cn}$ el proceso caratulado "Sociedad Quote Food Products B.I.". 
El principio general en el Derecho Procesal chileno es que el llamado de las partes a conciliación es facultativo para el árbitro, quien puede hacerlo cuantas veces estime pertinente, conforme a lo dispuesto en el inciso final del artículo 268 del CPC, con tal que el demandado ya haya contestado la demanda. En la práctica, en los arbitrajes comerciales domésticos las partes suelen facultar al árbitro, en las respectivas actas de procedimiento arbitral, para llamar a conciliación cuando así lo estime conveniente. No obstante el carácter eminentemente facultativo del llamado de las partes a conciliación conforme a la legislación procesal nacional, a partir del año 1994, y más precisamente desde la dictación de la Ley $\mathrm{N}^{\circ} 19.334$, de fecha 7 de octubre de 1994, el árbitro se encuentra obligado, aunque nada se diga al respecto en el acta de procedimiento arbitral, a llamar a las partes a conciliación al menos una vez durante el arbitraje, más precisamente una vez terminado el período de discusión -esto es, cuando las partes ya han intercambiado sus escritos sobre el fondo de la disputa- y antes de que comience el período de prueba del arbitraje. Siguiendo dicho imperativo, por ejemplo, el Reglamento Procesal de Arbitraje Doméstico del CAM Santiago indica en su artículo 24 que "El tribunal, presentado el escrito de contestación a la demanda o a la reconvención, en su caso, o vencido los plazos para hacerlo, llamará a las partes a conciliación".

Es justamente este llamado obligatorio de las partes a conciliación por parte del árbitro el que reviste el carácter de "trámite esencial en primera instancia", cuya omisión trae aparejado que el proceso arbitral adolezca de un vicio inherente de nulidad. Según lo dispuesto en el artículo 796 del CPC, los árbitros arbitradores o de equidad son los únicos árbitros que se encuentran liberados de este trámite obligatorio ${ }^{24}$.

24. Para los árbitros ex aequo et bono en Chilc, los únicos "trámites esenciales en primcra instancia" que deben ser respetados en sus procesos arbitrales son aquellos scìalados en los numerales $I^{\circ}$ y $5^{\circ}$ del articulo 795 del CPC, ya citado y trascrito. Vid. tambièn sentencia dictada por la Corte de Apelaciones de Santiago con fecha 3 de abril de 1997 en el proceso caratulado "Algricola El Deliria Limitada y. Otros con Ruchefort Ernst, Lionef". 
El llamado de las partes a conciliación se materializa en una audiencia-denominada audiencia de conciliación- que se verifica con el árbitro y las partes que asistan. La gran particularidad de este trámite es que, conforme a lo dispuesto en los artículos 262 y 263 del CPC, durante la audiencia de conciliación el árbitro debe necesariamente actuar como amigable componedor y proponer personalmente a las partes bases de arreglo, procurando obtener un acuerdo total o parcial respecto del conflicto suscitado.

En atención a las amplias facultades de que goza el árbitro en el marco de una audiencia de conciliación, ha sido la propia ley, en el artículo 263 del CPC, quien se ha encargado expresamente de precisar que las opiniones que emite el árbitro durante esta "fase" de conciliación no lo inhabilitan para seguir conociendo y resolver finalmente la disputa, en caso que la conciliación finalmente no prospere. Esta precisión era absolutamente necesaria, pues en caso contrario las partes podrían haber intentado inhabilitar al árbitro por "prejuzgamiento"25. A este respecto, resulta interesante observar que el Reglamento Procesal de Arbitraje Internacional del CAM Santiago, incorporando una técnica propia de lo que hoy se conoce como Med/Arb (Mediación/Arbitraje), reproduce este mismo principio cuando en su artículo $12, N^{\circ} 3$ señala que

"Cuando un acuerdo arbitral disponga que un conciliador o mediador deba ser nombrado y el conciliador o mediador deba también actuar posteriormente como árbitro en caso que la conciliación o mediación fracase, una parte no podrá oponerse a que el conciliador o mediador sea nombrado árbitro, basándose únicamente en el hecho de que se desempeñó como conciliador o mediador en todos o ciertos asuntos ventilados en el arbitraje".

25. El articulo 195, $N^{\circ} 8$ del COT señala que es causal de implicancia “/... Haber el jues manifestado su dictamen sobre la cuestion pendicute con conocimicnto de los antecedentes necesarios para promun. ciar sentencia". 
Otro aspecto relevante de este trámite obligatorio es que en el marco de la audiencia de conciliación se rompe o al menos puede romperse el principio dispositivo que informa todo el procedimiento civil en Chile ${ }^{26}$, toda vez que conforme al artículo 266 del CPC el árbitro puede ordenar que se agreguen al procesos todos los antecedentes y medios probatorios que estime pertinentes para efectos de alcanzar una conciliación entre las partes.

En virtud de lo expresado, no cabe duda alguna que, por medio del trámite obligatorio del llamado de las partes a conciliación, la legislación procesal chilena confiere a un árbitro, por el solo ministerio de la ley, facultades de arbitrador, esto es, facultades para actuar en equidad, con el propósito concreto y específico de que intente lograr un acuerdo que ponga término al arbitraje, no obstante que las partes no le hayan atribuido dicha calidad en el compromiso o cláusula arbitral, y aún en el evento que las partes le hubieren prohibido al árbitro actuar de dicha forma.

La importancia de la conciliación en Chile como mecanismo de terminación de un arbitraje no es menor. En efecto y según las estadísticas del CAM Santiago, nada menos que un $30 \%$ de los arbitrajes nacionales seguidos conforme a sus reglas desde el año 1998 a la fecha se terminaron por medio de un acuerdo conciliatorio entre las partes en el marco del arbitraje en curso. En este caso y conforme a lo dispuesto en el artículo $267 \mathrm{del} \mathrm{CPC}$, se levanta un acta del acuerdo conciliatorio, la cual consigna las especificaciones del arreglo, es suscrita por el árbitro, las partes y el secretario, y "se estimará como sentencia ejecutoriada para todos los efectos legales", esto es, pasa a constituir un "equivalente jurisdiccional", un acto que sin haber emanado de la jurisdicción de los tribunales de justicia resuelve un conflicto jurídico con efectos equivalentes -la acción y la excepción de cosa juzgada- a los

26. El principio ưspositivo esta graficado en el articulo 10 đ́el COT, que señala que "Los tribunales no podrán ejercer su ministerio sino a petición de parte, salvo los casos en que la ley los faculte para proceder de oficio". 
El Arbitraje y la Conciliación: una mirada en los arbitrajes

nacionales $e$ internacionales con sede en Chile

que produce una sentencia emanada de un órgano jurisdiccional.

En cualquier caso, la conciliación no debe confundirse con otros equivalentes jurisdiccionales similares, pero no iguales, como son el avenimiento y la transacción.

El avenimiento es "el acuerdo de las partes para poner término a un juicio pendiente, en el cual no tiene intervención activa el tribunal, limitándose las partes a presentarlo para el conocimiento del órgano jurisdiccional" $\mathrm{y}$, conforme al artículo $434, \mathrm{~N}^{\circ} 3$ del CPC, debe ser otorgado ante un ministro de fe o ante dos testigos y aprobado por el órgano jurisdiccional para que tenga mérito ejecutivo ${ }^{27}$. La transacción, por su parte, es un verdadero contrato en que, conforme a lo establecido en el artículo 2460 del Código Civil de Chile, "las partes terminan extrajudicialmente un litigio pendiente $o$ precaven un litigio eventual, haciéndose concesiones reciprocas".

Si bien todos ellos producen el efecto de cosa juzgada, la conciliación se distingue del avenimiento y de la transacción por cuanto requiere necesariamente de la intervención y participación activa del órgano jurisdiccional, que promueve, facilita y propone el acuerdo conciliatorio; mientras que el avenimiento y la transacción sólo son sinónimos en cuanto ponen término a un litigio pendiente, más no en cuanto se precave un litigio eventual, lo que es propio y exclusivo de la transacción, al igual que el hecho de que la transacción, para que sea váli$\mathrm{da}$, requiere necesariamente que las partes se hagan concesiones recíprocas.

27. RODRÍGUEZ PAPIC, Ignacio, Juicio Ondinario de Mayor Cuantia, Quinta Edición, Editorial Juridica de Chile, 1995, p. 238.

312 Revista Ecuatoriana de Arbitrajt: 


\section{LA CONCILIACIÓN EN LA LACI}

Al igual que lo que ocurre en la Ley Modelo sobre Arbitraje Comercial Internacional de la CNUDMI de 1985 y 2006, la LACI no realiza mención expresa o implícita alguna a la conciliación.

En efecto, el único equivalente jurisdiccional al que se hace referencia en la LACI es a la transacción. El artículo 30 de la LACI señala:

“Transacción. 1) Si, durante las actuaciones arbitrales, las partes llegan a una transacción que resuelva el litigio, el tribunal arbitral dará por terminadas las actuaciones $y$, si lo piden ambas partes y el tribunal arbitral no se opone, hará constar la transacción en forma de laudo arbitral en los términos convenidos por las partes. 2) El laudo en los términos convenidos se dictará con arreglo a lo dispuesto en el artículo 31 y se hará constar en él que se trata de un laudo. Este laudo tiene la misma naturaleza y efecto que cualquier otro laudo dictado sobre el fondo del litigio"28.

La frecuente necesidad de hacer constar la transacción en un laudo arbitral proviene de que, en caso de incumplimiento de lo acordado por las partes, se tendrá que proceder a su cumplimiento forzado, para lo cual es sumamente aconsejable contar con un laudo arbitral "amparable" en la Convención de Nueva York ${ }^{29}$.

28. El articulo $34, N^{\circ} 1$ del Reglamento de Arbitraje de la CNUDMI tambien reconoce esta posibilidad al scîalar que "Si antes de que se dicte el lando, las parles convienen una transacción que restelva el litigio, el tribunal arbitral dictará una orden de conchusión del procedimiento o, si lo piden ambas partes y el tribunal lo acepta, registrará la transacción en forma de laudo arbitral en los términos convenidos por las partes. Este laudo no ha de ser necesariamente motivado". Asimismo, el articulo 26 del Reglamento de Arbitraje de la Corte de Arbitraje de la Cámara de Comercio Internacional prescribe que "Laudo por acuerto de las partes. Si las partes llegan a un arreglo después que el expediente haya sido entregado al Tribunal Arbitral de conformidad con lo previsto en el articulo I3. se dejará constancia de dicho arneglo en un Laudo por acuerto de las parles, siempre y cuando las partes asi to hay'an solicitado y el Tribunal Arbitral estí de acuerdo con dictarlo". Por último, el articulo $34, N^{\circ}$, letra b) del Reglamento Procesal de Arbitraje Internacional del CAM Santiago, aunque indirecta $\odot$ implicitamente, acepta que un arbitraje se termine por transacción al cstablecer que "El tribunal arhitral decidirá dar por terminadas sus actnaciones cuando: b. Las partes actuerden dar por terminadas las actuaciones arbitrales".

29. Para mayores detalles, vid. REDFERN, Alan, HUNTER, Martin, BLACKABY, Nigel y PARTASIDES, Constantine, Teoria y Prictica del Arbitraje Comercial Internacional, Cuarta Edición, La Ley, 2007 , p. 526. 
Así, la conciliación, en su acepción conforme a la legislación procesal chilena, que implica un verdadero desdoblamiento del árbitro para le permite transformarse, al menos temporalmente, en un verdadero mediador, no tiene reconocimiento en el arbitraje comercial internacional. En otros términos, no constituye una práctica propia del arbitraje comercial internacional que el árbitro o el tribunal arbitral propugnen, por su propia cuenta e iniciativa, un acuerdo entre las partes, fijando las bases para un eventual arreglo que ponga término al arbitraje.

La verdad es que ello no es de extrañar. En efecto, en gran parte del mundo la conciliación es considerada como sinónimo de mediación y ambas, a su vez, como una de las varias clases de mecanismos existentes para la resolución alternativa de disputas o ADR, dentro de las cuales no se encuentra el arbitraje. Así, se ha dicho que

«Por lo general, los términos 'mediación' y 'conciliación' son utilizados en forma indistinta; no existe consenso generalizado respecto de la definición que les corresponde. Históricamente, en el ámbito de la solución privada de controversias, se consideraba que el conciliador era una persona que llegaba un paso más allá que el mediador, por así decirlo, dado que el conciliador redactaba y proponía los términos del acuerdo que, en su opinión, reflejaba una solución justa. En la práctica, ambos términos parecen haberse combinado, si bien los abogados del common law tienden a hablar de 'mediación', mientras que los abogados del civil law generalmente se refieren a 'conciliación' ${ }^{30}$.

Tan ajena es la conciliación al arbitraje comercial internacional, al menos conceptualmente, que desde el año 1980 existe el Reglamento de Conciliación de la CNUDMI, y desde el año 2002, incluso, también existe una Ley Modelo de la CNUDMI sobre Conciliación Comercial Internacional, ambos instrumentos desconocidos en Chile ${ }^{31}$. De hecho, la propia resolución de la

30. REDFERN, Alan, HUNTER, Martin, BLACKABY, Nigel y PARTASIDES, Constantine, $o b$, cit., p. 104. 
Asamblea General de la CNUDMI que aprobó la Ley Modelo sobre Conciliación Comercial Internacional da cuenta de la equivalencia entre conciliación y mediación, y por tanto, aunque implícitamente, de sus diferencias con el arbitraje, al señalar que

"Reconociendo el valor para el comercio internacional de los métodos de solución de controversias comerciales en los que las partes en litigio solicitan a un tercero o terceros que les ayuden en su intento de resolver la controversia de manera amistosa; Observando que esos métodos de solución de controversias, a los que se alude con expresiones tales como conciliación y mediación y términos similares, se usan cada vez más en la práctica mercantil nacional e internacional en sustitución de los litigios judiciales [...]; Estimando que la Ley Modelo ayudará en medida significativa a los Estados a mejorar su legislación relativa al uso de técnicas modernas de conciliación o mediación y a formular legislación cuando no exista $[\ldots]^{\prime \prime 32}$.

Quizás si el Med/Arb, o mediación seguida de arbitraje, en que la persona del árbitro podría ser la misma que las ofició de mediador con anterioridad, sea la figura que actualmente tienda a reflejar de mayor medida la eventual interrelación que puede hipotéticamente existir entre la mediación/conciliación y el arbitraje, lo que en los arbitrajes nacionales conducidos en Chile, como ya vimos, constituye una práctica habitual y, es más, un imperativo legal, aunque no in limine litis sino que durante la tramitación misma del arbitraje. No obstante aquello, el Med/Arb no tiene aplicación generalizada a nivel mundial -aunque es reconocido como una posibilidad en el artículo 12 de la Ley Modelo de Conciliación Comercial Internacional de la CNUDMI- y ha sido objeto de críticas, al menos respecto de su operatividad práctica:

31. De hecho, actualmente tan solo 7 países del mundo han dictado leyes basadas en la Ley Modelo de b CNUDMI sobre Conciliación Comercial Internacional. Entre cllos se encuentran dos paises iberoamericanos: Honduras (2000) y Nicaragua (2005).

32. Quincuagésimo Segunda Sesión Plenario de la Asamblea General de la CNUDMI, 19 de noviembre de 2002. 
"En este proceso, las partes acuerdan que si la mediación no conduce a un acuerdo negociado, el mediador abandonará su rol de tal y adoptará la función de árbitro para decidir la controversia. Si bien el proceso se utiliza en EE.UU. (por ejemplo, en cuestiones laborales), los abogados consideran que plantea diversas interrogantes. Por ejemplo, ¿qué grado de franqueza puede esperarse en las conversaciones entre las partes y el mediador (incluida la posibilidad de informarle qué propuestas transaccionales estarian dispuestas a aceptar) cuando saben que podría suceder que éste deba desempeñarse como árbitro en la misma causa? ¿Y cómo puede el árbitro cumplir o aparentar cumplir los requisitos de 'imparcialidad' y 'audiencia justa' si anteriormente mantuvo conversaciones privadas con cada parte por separado y les dio a conocer sus opiniones?"33.

\section{Procedencia de la conciliación en los ARBITRAJES COMERCIALES INTERNACIONALES CON SEDE EN CHILE}

Todos quienes tienen algún conocimiento en materia de arbitraje comercial internacional saben, o se han visto forzados a aprender, que la sede del arbitraje reviste una importancia fundamental, toda vez que determina la lex arbitri, es decir, la ley nacional aplicable a todas las cuestiones de forma y fondo relativas al compromiso o cláusula arbitral y a la conducción del procedimiento arbitral ${ }^{34}$. Así, el contenido de la lex arbitri puede perfectamente determinar el éxito o fracaso de un arbitraje, con independencia del mérito de las alegaciones de fondo de las partes.

Como vimos, la LACI, que constituye la ley especial aplicable a los arbitrajes comerciales internacionales con sede en Chile,

33. REDFERN, Alan, HUNTER, Martin, BLACKABY, Nigel y PARTASIDES, Constantine, ob. cil., p. 107.

34. REDFERN, Alan, HUNTER, Martin, BLACKABY, Nigel y PARTASIDES, Constantine, $s h$. cit., p. I54 y ss; BORN, Gary B., International Commertial Arbitration, Comunentany and Alaterials, Second Edition. Transnational Publishers \& Kluwer Law International, 2001. p. 411 y ss. 
no hace referencia alguna y omite toda mención a la conciliación. Al mismo tiempo, no obstante, la legislación procesal chilena aplicable al arbitraje doméstico, que constituye la ley supletoria de la LACI en todas aquellas materias no reguladas por ella ${ }^{35}$, establece la conciliación como un trámite esencial en los arbitrajes conducidos en Chile, con excepción de los procesos arbitrales ventilados ante árbitros ex aequo et bono. En consecuencia y atendido lo expuesto precedentemente, el practicante en materia de arbitraje comercial internacional puede -e incluso debe- legítimamente hacerse la siguiente pregunta: si designo a Santiago de Chile como la sede de mi arbitraje comercial internacional, ¿será indispensable que se realice una conciliación durante la secuela del arbitraje y, en la afirmativa, puede el árbitro que llevó adelante las gestiones de conciliación seguir conociendo y resolver el arbitraje si éstas fracasan?

Aunque parezca redundante, es necesario insistir, en primer lugar, que esta interrogante no se plantea tratándose de arbitrajes comerciales internacionales con sede en Chile que sean ventilados y resueltos por un árbitro arbitrador, en equidad o $e x$ aequo et bono, toda vez que ni la LACI ni la legislación procesal chilena exigen que se realice el trámite de conciliación en el marco de arbitrajes de esta naturaleza. Entendemos, eso sí, que los arbitrajes de equidad constituyen a todas luces una excepción tratándose de arbitrajes comerciales internacionales, por lo que la cuestión planteada no reviste mayor trascendencia en este caso.

La respuesta a la cuestión planteada no reviste mayor complejidad cuando las partes, ejerciendo la autonomía de su libertad ya sea en el compromiso, en la cláusula arbitral o durante la misma secuela del arbitraje comercial internacional con sede en Chile, han convenido expresa o tácitamente -por ejemplo, al aceptar, no objetar y participar en una audiencia que con tal pro-

35. SALVADOR CRESPO, lñigo, "Especialidad y Prevalencia de la Ley Arbitral sobrc las Normas de Derecho Procesal Común", en Revista Ecuatoriana de Arhitraje, Cevallos Editora Juridica, 2009. p. 83. 
pósito hubiese sido convocada por el árbitro- en que se realice una conciliación con miras a que el árbitro, actuando con carácter de amigable componedor, proponga personalmente a las partes bases para un eventual acuerdo que ponga término al arbitraje.

En este escenario y suponiendo el fracaso de las gestiones de conciliación, creemos que el árbitro no estaría inhabilitado para seguir conociendo y resolver el arbitraje comercial internacional con sede en Chile. Sustenta lo anterior lo dispuesto en la Norma General 4(d) de las Directrices de la IBA sobre los Conflictos de Intereses en el Arbitraje Internacional, aprobadas por el Consejo de la International Bar Association el 22 de mayo de 2004, que señala que

"En cualquier etapa del procedimiento el árbitro podrá asistir a las partes para llegar a una transacción que resuelva la controversia. Sin embargo, antes de hacerlo, el árbitro deberá obtener el consentimiento expreso de las partes de que el actuar de esa forma no lo descalificará para seguir desempeñando las funciones de árbitro. Dicho consentimiento expreso será considerado como una renuncia efectiva al derecho que tienen las partes a objetar cualquier conflicto de intereses que pudiera surgir derivado de la participación del árbitro en dicho proceso conciliatorio o por la información a la que el árbitro pueda tener acceso en dicho proceso. Si a pesar del apoyo del árbitro no se llegare a un acuerdo conciliatorio, la renuncia de las partes seguirá siendo válida. No obstante, en consonancia con la Norma General 2(a) y a pesar de la renuncia de las partes, el árbitro deberá renunciar si, como consecuencia de su participación en el proceso conciliatorio, se generan dudas que le impidan mantener su imparcialidad e independencia en las siguientes instancias del procedimiento"36.

36. Comentando la Noma General 2(d), las mismas Directrices de la IBA sobre los Conflictos de Intereses en el Arbitraje Intemacional establecen que "Algunas jurisdicciones, atuntue no todas, aceptan que el Tribunal Arbitral ayude a las partes a buscar un acuerdo transaccional en cualyuicr momento del procedimiento. El consentimiento previo de las partes para que el Tribual Arbitral proceda en este scutido, tomamdo en consideración plenamente las consccucncias de cste acto, constitu- 
Salvo por este último párrafo, que en forma excepcional aunque teóricamente permitirían a una parte inhabilitar efectivamente o al menos intentar inhabilitar a un árbitro como consecuencia de su participación en gestiones de conciliación realizadas en el marco de un arbitraje comercial internacional con sede en Chile, la legislación procesal chilena es plenamente concordante con la Norma General 2(d) de las Directrices de la IBA sobre los Conflictos de Intereses en el Arbitraje Internacional, en cuanto excluye expresamente toda posibilidad de que las partes puedan siquiera intentar impugnar a un árbitro que haya participado en gestiones de conciliación durante la secuela de un arbitraje, lo que no es sino la consecuencia lógica, directa y necesaria de que la legislación procesal chilena permite e incluso exige, por regla generalísima, que se verifique una conciliación durante los arbitrajes. Dado su carácter de lex arbitri, conformada además por normas de Derecho Público contenidas en el $\mathrm{CPC}$, no cabe duda alguna que en caso de cualquier discrepancia en esta materia, como la arriba reseñada, la legislación procesal chilena prevalece sobre las Directrices de la IBA sobre los Conflictos de Intereses en el Arbitraje Internacional, las que como su propio nombre indica son sugerencias y "no son normas juridicas y no prevalecen sobre el Derecho nacional aplicable ni sobre el reglamento de arbitraje que las partes hubieren elegido" ${ }^{37}$.

La gran interrogante consiste en determinar si, en el marco de un arbitraje comercial internacional con sede en Chile, y a falta de acuerdo explícito o implícito de las partes al respecto, es necesario que el árbitro realice una gestión de conciliación en los

ye una remucia efectiva de las partes a hacer valer su derecho de objetar al arbitro por un posible conflicto de intereses. Generalmente basta con que las partes expresen su conse'ntimiento verbalmente; por el contrario, en algunas jurisdicciomes debe prestarse por escrito en un documento firmade. En la práctica, el requisito de que la renuncia sea expresa se cumple cuando las partes manifiestan su consentimiento en el acta o en la trascripción de la audiencia conciliatoria. Además, para evitar que las partes usen al árbitro como conciliador para luego descalificarlo, la Norma General hace hincapic en que la remuncia sigue siendo válida a pesar de que la conciliación fracase. De esta mane$r a$, las partes asumen el riesgo de que el árbitro obtenga todo tipo de informacién sobre las partes al biscar un acuerdo. Por lo tanto, antes de dar su consentimiento expreso. Ias partes deben sopesar las consecuencias y acondar una regulacion sobre esta sifuacion si asi lo estimaran necesario".

37. Directrices de la IBA sobre los Conflictos de Intereses en el Arbitraje Internacional, Introducción, N 6. 
términos que son propios y característicos para la legislación procesal chilena.

Nuestra opinión es que no es indispensable, como requisito de validez ni del proceso arbitral ni del laudo arbitral definitivo, que se verifique una conciliación en los arbitrajes comerciales internacionales con sede en Chile, sino que ello queda sometido al arbitrio absoluto de las partes. Esta opinión se funda:

(i) En que, como vimos, la LACI, que constituye la ley especial aplicable al arbitraje comercial internacional en Chile, no se refiere ni en forma explícita ni implícita a la conciliación;

(ii) En que, como también analizamos, la conciliación es una práctica que por regla generalísima es ajena y extraña al arbitraje comercial internacional, toda vez que se trata de un mecanismo de resolución alternativa de disputas equivalente a la mediación y, por tanto, conceptualmente distinto al arbitraje;

(iii) En que la conciliación, si bien por regla generalísima constituye un trámite esencial y obligatorio en el marco de arbitrajes nacionales, no es una gestión que forme parte integrante de la garantía del debido proceso establecida en el artículo $19, \mathrm{~N}^{\circ} 3$, inciso $5^{\circ}$ de la Constitución Política de la República de Chile ${ }^{38} y$, en consecuencia, no forma parte del "orden público procesal" indisponible para las partes ${ }^{39} ; y$

38. "La Constitucion asegura a todas las personas: (...) Toda sentencia de un órgano que ejerza jurisdicciön dehe findarse en um proceso previo legalmente tramitado. Cornesponderá al legislador estahlecer siempre las garantias de un pmecedimiento y una investigacioin racionales y justos".

39. La Corte Suprema, en sentencia pronunciada con fecha 5 de diciembre de 2001 en el proceso Rol $\mathrm{N}^{\circ} 36+3-2001$, resolvió que "Conforme a la doctrina nacional, el derecho a un proceso previo, legalmente tramitado, racional y justo, que la Constitución Politica de la Repriblica asegura a todas las personas, debe contemplar las signientes garantias: La pablicidad de los actos jurisdiccionales, el derecho a la acción. el oportuno conocimicnto de ella por la parte contraria, el emplazamiento, atecuada ascsoria y defensa con abogados, la producción libre de pricbas conforme a la lev, el cxamen y objeciön de la evidencia rendida, la bilateralidad de la audiencia, la facultad de interponer recursos para revisar las sentencias dictadas por tribunales inferiores, el pmonutciamiento de los fallos dentro de los plazos legales previstos y la fumdamentación de ellos en el régimen juridico sigente, 0 . en su defecto, en los principios generales del derccho y equidad natural". 
(iv) En que, cualquiera que sea en definitiva su verdadera naturaleza jurídica, un arbitraje comercial internacional, aunque tenga su sede en Chile, no puede equiparse en forma absoluta a un arbitraje nacional ${ }^{40}$.

Sin perjuicio de todas estas consideraciones, estimamos que en el caso de arbitrajes comerciales internacionales cuya sede se encuentre en Chile resulta aconsejable y prudente excluir la conciliación en forma expresa -ya sea en el compromiso, en la cláusula arbitral o en el acta de procedimiento arbitral-si es que las partes no estiman conveniente la práctica de dicha diligencia durante el curso del arbitraje.

\section{COnClusiones}

En el marco del arbitraje doméstico en Chile, existe una verdadera y profunda "simbiosis" entre el arbitraje y la conciliación. Tanto es así, que la propia legislación procesal chilena se encarga de precisar que, con excepción de los arbitrajes de equidad, el llamado de las partes a conciliación por parte del propio árbitro constituye un "trámite esencial en primera instancia" cuya omisión puede traer aparejada la nulidad del procedimiento arbitral o del mismo laudo arbitral. En virtud de ello, son muchos los arbitrajes nacionales que terminan por medio de una conciliación, en que el árbitro ha sido el encargado de proponer personalmente a las partes bases de arreglo, actuando con el carácter de amigable componedor. $\mathrm{Si}$ las gestiones de conciliación del árbitro no arriban a buen puerto entre las partes, el árbitro no queda inhabilitado en forma alguna para seguir conociendo y resolver el arbitraje en cuestión.

40. Vid. VASQUEZ PALMA, MARIA FERNANDA, ob. cit., p. 131: "Los árbitws del arbitraje internacional no pueden comprenderse dentro del mareo señalado para el Derecho interno, son sencilla mente entes privados que desarrollan la fimción de juzgar por reguerirlo la volumtad de las partes [...]. Asi. esta ley [la LACI] nace de manera completamente independiente, no incorporada a ninguno de los Códigos procesales, lo que ciertamente presenta un claro reconocimiento a la autonomia de la institución. 
El Arbitrajc y la Conciliaciôn: una mirada en los arbitrajes

nacionales e internacionales con sede en Chile

En el arbitraje internacional, por su parte, el arbitraje y la conciliación son instituciones autónomas y con vida propia. De hecho, la realización de gestiones de conciliación por el propio árbitro en el marco de un arbitraje en curso constituye una práctica extraña al arbitraje comercial internacional. Si Chile efectivamente busca y desea convertirse en una sede atractiva de arbitrajes comerciales internacionales que involucren a partes iberoamericanas, principalmente, es evidente que su legislación, doctrina y jurisprudencia deben adaptarse plenamente a lo que constituye la costumbre internacional en la materia. Como vimos, no cabe duda alguna que las partes pueden pactar $-y$ dicho acuerdo será respetado- que el árbitro realice una audiencia de conciliación en el marco de un arbitraje comercial internacional con sede en Chile, sin que el eventual fracaso de esta gestión traiga aparejada consecuencia alguna para el árbitro. Por otro lado y como probablemente será la regla general, las partes pueden perfecta y válidamente excluir, ya sea expresa o tácitamente, que se realicen gestiones de conciliación en el marco de un arbitraje comercial internacional con sede en Chile, acuerdo que también debería ser respetado porque el llamado de las partes a conciliación no puede considerarse un "trámite esencial en primera instancia" aplicable en el marco de arbitrajes comerciales internacionales que se realicen en nuestro país.

La doctrina y la jurisprudencia nacionales aún no se han pronunciado sobre esta materia tratándose de arbitrajes comerciales internacionales con sede en Chile. Es de esperar -y todo pareciera indicar que así será, atendido los precedentes doctrinales y jurisprudenciales relativos a otros asuntos similares- que, llegado el momento oportuno, nuestros juristas se pronuncien correcta y sabiamente al respecto para así dar un fuerte impulso a Santiago de Chile como una sede factible de arbitrajes comerciales internacionales que involucren a partes iberoamericanas, sin imponerles requerimientos formales que son ajenos a la práctica habitual en materia de arbitraje comercial internacional en el mundo entero. 